This item was submitted to Loughborough's Research Repository by the author.

Items in Figshare are protected by copyright, with all rights reserved, unless otherwise indicated.

\title{
Practice improves court mobility and self-efficacy in tennis-specific wheelchair propulsion
}

\section{PLEASE CITE THE PUBLISHED VERSION}

https://doi.org/10.1080/17483107.2020.1761892

\section{PUBLISHER}

Taylor \& Francis

\section{VERSION}

AM (Accepted Manuscript)

\section{PUBLISHER STATEMENT}

This is an Accepted Manuscript of an article published by Taylor \& Francis in Disability and Rehabilitation: Assistive Technology on 15 May 2020, available online:

http://www.tandfonline.com/10.1080/17483107.2020.1761892.

\section{LICENCE}

CC BY-NC-ND 4.0

\section{REPOSITORY RECORD}

Sindall, Paul, John Lenton, Barry Mason, Keith Tolfrey, Rory Cooper, Kathleen Martin Ginis, and Vicky Goosey-Tolfrey. 2020. "Practice Improves Court Mobility and Self-efficacy in Tennis-specific Wheelchair Propulsion”. Loughborough University. https://hdl.handle.net/2134/12205316.v1. 


\title{
Practice improves court-mobility and self-efficacy in tennis-specific wheelchair propulsion
}

\author{
Authors: \\ Sindall, Paul; University of Salford, School of Health \& Society; Loughborough University, School of \\ Sport, Exercise \& Health Sciences \\ Lenton, John; Loughborough University, School of Sport, Exercise and Health Sciences \\ Mason, Barry; Loughborough University, School of Sport, Exercise \& Health Sciences \\ Tolfrey, Keith; Loughborough University, School of Sport and Exercise Sciences \\ Cooper, Rory; University of Pittsburgh, Human Engineering Research Laboratories, Rehabilitation \\ Research and Development Service, Department of Veterans Affairs, and Departments of Rehabilitation \\ Science \& Technology and Physical Medicine \& Rehabilitation \\ Martin Ginis, Kathleen; The University of British Columbia \\ Goosey-Tolfrey, Victoria; Loughborough University, School of Sport and Exercise Sciences
}

\begin{abstract}
Purpose: Wheelchair tennis (WT) chair propulsion is uniquely characterised by the requirement for racket-holding coupled with effective hand-rim contact. Thus, investigations involving strategies to enhance chair mobility skills are merited. The aim was to examine effects of organised practice on WT match-play responses and the impact of racket-holding during practice.

Materials and methods: Following physiological profiling involving graded and peak exercise testing, sixteen able-bodied (AB) participants performed bouts of WT match-play interspersed with practice involving wheelchair mobility drills completed with (R) or without (NR) a tennis racket. A data logger recorded distance and speed. Self-efficacy was reported.

Results and conclusions: Significant main effects for match revealed higher post-practice overall and forwards distances $(P<0.05)$, peak $(P<0.005)$ and average $(P<0.05)$ speeds, and self-efficacy $(\mathrm{SE})(P=0.001)$ were attained. During practice, lower distances and speeds were achieved with $R$, with a lower physiological cost than NR. Practice increases courtmovement and SE with no associated increases in physiological cost. Changes represent enhanced court-mobility. Differences between practice characteristics provide options for skill development and optimisation of health outcomes.
\end{abstract}




\section{Introduction}

Wheelchair tennis (WT) court skills are transferable to everyday life situations, increasing independence, enhancing quality of life and increasing psychosocial wellbeing in those who participate regularly [1]. However, leisure time physical activity is typically low in spinal cord injured populations [2] with attitude towards physical activity being an important determinant of behaviour [3]. For this reason, consideration of strategies to facilitate participation in WT potentially confers considerable benefit.

Chair-based skills training has potential to enhance participation in chair-based activity and thereby, positively influence quality of life in adult populations with an SCI [4]. Consequently, considerable interest has been placed on the development and validation of novel wheelchair skills tests. Since an observer-based test reported good validity and reliability [5], further objective [6] and subjective [7] test variants have been proposed, with the former being preferable where practicable [8]. Whilst these tests demonstrate acceptable validity and reliability, the focus has been on daily manual wheelchair use in non-sport settings. Moreover, considerable differences in methodologies and variation in test characteristics have made comparison of outcomes problematic [9]. Wheelchair court-sports (i.e. tennis, basketball, rugby), involve high speeds [10], with tennis involving intermittent activity [11,12] and a requirement for timely reactions to ball and opponent displacement $[13,14]$. Collectively these characteristics represent a unique physiological and skill challenge [15], emphasising the need for specific testing for sports chair users [16]. Promisingly, tennisspecific field tests have recently been validated for wheelchair tennis [17] albeit only for highly skilled players.

Successful WT performance requires adequate court-mobility. Inadequate movement results in poor positioning, timing and shot execution, leading to errors and reduced rally duration [18]. Elite players navigate the court at high speeds, covering greater distances than low-skill counterparts, due to an advanced ability to react and respond to ball movement [14] As self-efficacy (SE) is a function of skill-level, elite able-bodied (AB) players report a higher SE than low-skill counterparts and therefore benefit from positive perceptions of anxiety control and a positive performance outlook [19]. In contrast, low SE is associated with low perceptions of control, problems with focus, concentration and debilitating effects on performance [19]. Participation in adapted sports positively influences self-esteem, SE and physical wellbeing [20]. Thus, for performance gains, optimisation of the interface between athlete and chair is essential [21]. So that novice WT players do not become disillusioned with core techniques at early, developmental stages, consideration of strategies for improving skill, and thereby increasing SE, are merited. Such studies will facilitate an examination of associations with factors which may promote longer-term participation, and thus, offer a suitable stimulus for chronic health adaptations.

While WT training across a spectrum of exercise intensities is generally recommended [11], specific strategies for health and performance benefits remain unclear. Off-court aerobic training is advocated for cardiovascular fitness development in WT players [12], with wheelchair exercise, arm-crank ergometry and resistance training being viable modes [22]. However, sole reliance on fixed-path strategies is problematic, as training should reflect competitive demands, namely performance of complex, multi-directional movements [12], in response to opponent and ball position [13,14], at relative intensities $>70 \%$ peak heart rate (HR) [14]. Furthermore, players must push with a racket. This constraint is associated with decreased push time, unfavourable contact angles and restricted power output [23] and hence, reduced propulsion speed and acceleration [15]. Use of a novel square profile handrim does not seem to improve the WT propulsion technique [24]. However, increasing propulsion speed does enable enhanced WT court-movement and court-positioning [14]. Therefore, consideration of specific on-court training activities may yield better outcomes. 
Carefully selected AB individuals have no experience of wheelchair propulsion. Therefore, experience is not a confounding factor. Where persons who use a wheelchair are sampled, large variability in chair experience and age characterise the sample [4-7]. Prior studies have utilised $\mathrm{AB}$ populations to good effect, for example, identifying changes in mechanical efficiency with practice [25], and differences in propulsion technique [26]. Hence, sampling this group can be considered ideal for prospective research designs which investigate the rate and / or the magnitude of improvement from baseline (i.e. no experience at all), and to enable comparisons to be made between modes, methods or training-types.

Inexperienced persons who use a wheelchair can improve mechanical efficiency in short periods of practice [27]. Following two 60-min practice sessions, improvements in SE of chair use and problem-solving were noted [28]. However, less is known about short-term interventions designed to improve sports-propulsion, where the physical environment is more complex and challenging. A low-compression ball allows low-skill players to push further and faster [13], offering potential for court-mobility enhancement. While greater courtmovement has been linked with enhanced perceptual ability to reach the ball after an opponent's shot [13], yet no information exists currently to support improved SE in shot-play and chair propulsion when using a modified ball or for any other player development strategies.

Therefore the purpose of this study was to determine possible differences in courtmovement, physiological cost and SE in match-play following practice and racket-holding. It was hypothesised that greater court-movement, elevated physiological cost and higher SE would be observed post- compared with pre-match practice, with greater changes observed after practice with a racket.

\section{Materials and Methods}

\section{Participants}

Sixteen AB participants (12 male and 4 female) provided written consent to participate study. All testing protocols were submitted to, and subsequently approved by the University Ethics Committee, with all testing processes conducted according to recognised ethical standards for testing of human subjects. Participants were right-handed, with no prior wheelchair propulsion nor previous WT playing experience.

\section{Procedures and instrumentation \\ Physiological profiling}

Baseline resting data for oxygen uptake $\left(\dot{\mathrm{V}}_{2}\right)$ were obtained during 5-min motionless rest and a 3-min familiarisation stage completed on an arm-crank ergometer with adjustable cranks (range: 80 to $170 \mathrm{~mm}$ ) (Lode Angio, Groningen, The Netherlands). Participants were seated (chair without arms), with shoulder joint alignment to the pedal axle and slight elbow flexion at maximal arm extension. Four to six 3-min steady-state exercise bouts were followed by consecutive 1-min bouts to exhaustion for assessment of submaximal responses and determination of peak oxygen uptake $\left(\dot{\mathrm{V}}_{2 \text { peak }}\right.$ ) (figure 1). Verbal feedback ensured maintenance of desired cadence $\left(75 \mathrm{rev} \cdot \mathrm{min}^{-1}\right)$, with test-termination after three warnings (< $\left.70 \mathrm{rev} \cdot \mathrm{min}^{-1}\right)$. Expired air samples were collected and analysed using an online metabolic cart (Metalyzer 3B, Cortex Medical, Leipzig, Germany). HR was monitored continuously at 1-s intervals via radio telemetry (RS400 Polar Sport Tester, Kempele, Finland) during physiological profiling and on-court activity. Valid criteria for $\mathrm{V}_{2 p e a k}$ were determined as previously described [13]. 


\section{On-court activity: match-play}

Player numbers were assigned ( 1 to 16$)$ with two groups $(n=8)$ randomly allocated to one of two testing days (figure 1). Opponents were assigned based on physiological profiling and sex. Participants completed a WT match-play bout prior (PRE) to organised practice involving WT-specific mobility drills. For practice, participants were randomly allocated to racket (R) and no-racket (NR) groups, with a final bout of match-play completed (POST). Participants were allocated one of four sports wheelchairs (Invacare TopEnd Pro Tennis). Players used the same chair for all conditions. Wheel sizes and tyre pressures were standardised (wheel diameter: $61.4 \mathrm{~cm}$ and 120 psi respectively) with tyres checked immediately prior to on-court use.

\section{[figure 1 near here]}

Match-play characteristics were aligned to recreational playing conditions. Play duration was aligned to mimic recreational facility court-booking systems, involving 60-min of physical activity. Players kept their own score, changed ends for their second bout and were expected to retrieve balls between points. No external support or coaching was provided.

Testing was completed on two days using the same two hard courts at an indoor tennis centre. Ambient conditions were similar (day 1 vs. 2 mean environmental temperature: $18, \mathrm{~s}=1 \mathrm{vs} .16, \mathrm{~s}=1^{\circ} \mathrm{C}$, mean atmospheric pressure: $1002, \mathrm{~s}=9 \mathrm{vs} .997, \mathrm{~s}=5 \mathrm{mmHg}$, mean relative humidity: $40, \mathrm{~s}=2 \mathrm{vs} .52, \mathrm{~s}=4 \%$ ). An independent observer timed matches using a stopwatch and enforced changeovers. Participants completed a 10-min warm-up (propulsion, no racket) prior to bout one. Two new green-rated LCBs were issued for each bout and were not reused. Balls are recommended by the International Tennis Federation (ITF) for novice users [18].

\section{On-court activity: organised practice}

Eight WT-specific drills for WT court-mobility [29] were included (figure 1). Participants completed drills within-groups (i.e. $\mathrm{R}=8, \mathrm{NR}=8$ ). Both sides of two courts were used. Drills were completed in sequence (figure 1). Activity was continuous (3-min). A 2-min recovery period allowed for explanation of the next drill. Players were instructed to start and stop at the same time. To eliminate an order effect, racket and drill sequences were randomised within- and between-groups (figure 1). Session duration was $\sim 40$-min with participants completing $\sim 24$-min of activity (i.e. 8 x 3-min).

\section{Court-movement variables}

Data logger usage has been described previously $[13,14]$ with appropriateness for WT confirmed [30,31]. In the present study, one data logger was fitted to each wheel. This approach is advocated for accurate and reliable court-movement data collection [30]. Right and left loggers were averaged for calculation of distance (overall, forwards, reverse, forwards-to-reverse) and speed (peak, average). An averaging interval of 1-s was used [32]. The use of mean distance per minute $(\mathrm{m})$ allowed for comparison to previous work [14] where between-group comparisons involving variable match duration merited calculation of relative units. Percentage time in speed zones was reported according to previous approaches $[13,31]$.

\section{Physiological variables}

$\mathrm{HR}$ was expressed as absolute and as a percentage of laboratory-based maximum $\left(\% \mathrm{HR}_{\mathrm{L}}\right)$. Peak and minimum HRs were recorded. For estimation of oxygen uptake during WT match- 
play $\left(\dot{\mathrm{V}}_{2 \mathrm{~T}}\right)$ and organised practice $\left(\dot{\mathrm{V}}_{2 \mathrm{P}}\right), \mathrm{HR}$ and $\dot{\mathrm{VO}}_{2}$ from laboratory testing were regressed using a standard linear model. For ease of reference, $\dot{\mathrm{VO}}_{2 \mathrm{~T}}$, relative exercise intensity during organised practice $\left(\% \dot{\mathrm{V}} \mathrm{O}_{2 \mathrm{P}}\right)$, and energy expenditure $(\mathrm{EE})$ were calculated using previously described formulae [13].

\section{Self-efficacy}

A questionnaire previously used to measure task-specific SE in a mixed-sex sample of physically impaired individuals after participation in a single WT session [33] was administered by interview immediately-post match-play bouts. Five questions were scored on a 7-point Likert scale with anchors 1 (not at all confident) to 7 (completely confident) with the mean value representing the scale score. Adequate internal consistency ( $\alpha=0.79$ to 0.99 ) has previously been reported across all time points [33].

\section{Statistical analyses}

SPSS (version 20.0, SPSS Inc., Chicago, IL, USA) was used for all statistical analyses. Descriptive statistics (mean, $\pm \mathrm{s}$ ) were obtained for all measures. Normality was confirmed by the Shapiro-Wilk test. Homogeneity of variance was confirmed by Mauchly's and Levene's tests for respective within-participant and between-group measures. An independent samples $t$-test confirmed no significant between-group differences in $\dot{\mathrm{VO}}_{2 \text { peak. }}$ Grubbs' test [34] was used to remove significant outliers in raw 1 -s distance data $(P<0.05)$. HR values were presented as absolute (mean peak, mean minimum and mean average HR) and relative $\left(\% \mathrm{HR}_{\max }, \% \mathrm{HR}_{\min }, \% \mathrm{HR}_{\mathrm{avg}}\right)$ playing intensities. To examine the combined effect of organised practice and racket-strategy on match-play, separate 2 × 2 (match-by-group) mixed-measures ANOVAs were applied for all dependent variables. Prior to ANOVA, internal consistency of responses for the SE scale score was confirmed using Chronbach's alpha $(\geq 0.7)$, with separate checks performed on PRE and POST data. Partial Eta squared $\left(\eta^{2}\right)$ and Cohen's $d$ [35] were calculated to determine effect size for ANOVA and betweengroup comparisons respectively. Calculations for $\eta^{2}$ p were made by-hand (not in SPSS) using:

$$
\eta_{\mathrm{p}}^{2}=\text { sum of squares effect / (sum of squares effect }+ \text { sum of squares error) }
$$

Descriptors for worthwhile effects were applied $\left(\eta^{2}\right.$ : large $>0.138$, medium $>0.059$, small $>0.010 ; d$ : very large $\geq 1.3$, large $\geq 0.8$, medium $\geq 0.5$, small $\geq 0.2$ ) [35]. Independent samples $t$-tests examined between-group differences in physiological responses and courtmovement variables for $\mathrm{R}$ and NR. Relative EE was obtained to determine the match-play duration to enable a 300 to $350 \mathrm{kcal}$ yield. Statistical significance was accepted at a level of $P$ $<0.05$. Ninety-five percent confidence intervals $(95 \% \mathrm{CI})$ were reported.

\section{Results}

All participants attained $\dot{\mathrm{VO}}_{2 \text { peak }}$ in accordance with test-termination criteria. A nonsignificant between-group difference in $\dot{\mathrm{V}} \mathrm{O}_{2 \text { peak }}(P=0.630, d=0.11)$ indicated participants were suitably matched for aerobic capacity ( $\mathrm{R} v$ s. NR: 33.0, $\mathrm{s}=6.7$ vs. $33.9, \mathrm{~s}=9.2$ $\mathrm{ml} \cdot \mathrm{kg} \cdot \mathrm{min}^{-1}$ ). Internal consistency of the SE scale score was confirmed (PRE $\alpha=0.76$, POST $\alpha=0.88)$.

\section{Combined effect of practice and racket-strategy on match-play}

A large but non-significant interaction was observed for forwards-to-reverse distance $(P=$ $\left.0.139, \eta_{\mathrm{p}}^{2}=0.150\right)$. Match-by-group interactions for all other performance variables were not significant. Independent of racket-strategy, the main effect for match revealed higher overall distances $(P=0.042)$, forwards distances $(P=0.012)$, mean peak speeds $(P=0.004)$ mean 
average speeds $(P=0.036)$ and SE $(P=0.001)$ for match-play completed POST practice (table 1). Effects were large $\left(\eta^{2} \mathrm{p}=0.263\right.$ to 0.533$)$. Physiological variables were not affected by match. Relative match-play intensity was consistently low $\left(\% \dot{\mathrm{VO}}_{2 \mathrm{~T}}\right.$ : <30\%). Main effects for group were not significant.

\section{[table 1 near here]}

\section{Effect of racket-holding on court-movement and physiological variables during practice} Independent $t$-tests revealed lower court-movement for $\mathrm{R}$, with lower overall $(64, \mathrm{~s}=10 \mathrm{vs}$. $83, \mathrm{~s}=15 \mathrm{~m}, P=0.010)$, forwards $(47, \mathrm{~s}=10 \mathrm{vs} .61, \mathrm{~s}=10 \mathrm{~m}, P=0.013)$ and reverse distances $(5, \mathrm{~s}=2$ vs. $8, \mathrm{~s}=3 \mathrm{~m}, P=0.040)$. $\mathrm{R}$ achieved lower peak $(2.8, \mathrm{~s}=0.4 v s .3 .4, \mathrm{~s}=$ $0.6 \mathrm{~m} \cdot \mathrm{s}^{-1}, P=0.031$ and average speeds $\left(1.1, \mathrm{~s}=0.2 \mathrm{vs} .1 .4, \mathrm{~s}=0.3 \mathrm{~m} \cdot \mathrm{s}^{-1}, P=0.010\right.$ and achieved lower relative mean peak exercise intensities $(68, \mathrm{~s}=9$ vs. 78, $\mathrm{s}=9 \%, P=0.029)$. Effect sizes ranged from large to very large $(d=1.19$ to 1.48$)$. Large, but non-significant effects were noted for $\% \mathrm{HR}_{\mathrm{avg}}(P=0.065, d=1.00), \dot{\mathrm{V}} \mathrm{O}_{2 \mathrm{P}}(P=0.103, d=0.81)$ and $\% \dot{\mathrm{VO}}_{2 \mathrm{P}}$ $(P=0.126, d=0.88)$. No further between-group differences in physiological variables were significant, with medium to trivial effect sizes (figure 2).

\section{[figure 2 near here]}

While relative EE was also not significantly different between groups $(P=0.098)$ a large effect size $(d=0.88)$ showed a tendency for lower EE in $\mathrm{R}\left(4.0, \mathrm{~s}=1.6 \mathrm{kcal} \cdot \mathrm{min}^{-1}\right)$ than $\mathrm{NR}\left(5.9, \mathrm{~s}=2.6 \mathrm{kcal} \cdot \mathrm{min}^{-1}\right)$. Hence, a higher target activity duration for cardiovascular health enhancement is associated with $\mathrm{R}(75.8$ to $88.4 \mathrm{~min})$ than NR (51.2 to $59.7 \mathrm{~min})$. R spent more time than NR within one relatively low speed zone (figure 3: 0.5 to $0.99 \mathrm{~m} \cdot \mathrm{s}^{-1}, P=$ $0.020, d=1.29$ ). In contrast, $\mathrm{R}$ were significantly less active in two higher speed zones approaching top speed (2.00 to $2.49 \mathrm{~m} \cdot \mathrm{s}^{-1}, P=0.011, d=1.46 ; 2.50$ to $2.99 \mathrm{~m} \cdot \mathrm{s}^{-1}, P=0.012$, $d=1.45)$. Time in speed zones 7 and $8\left(>3.00 \mathrm{~m} \cdot \mathrm{s}^{-1}\right)$ was negligible.

\section{[figure 3 near here]}

\section{Discussion}

Greater overall and forwards distances, and higher peak and average speeds were achieved in WT match-play, post-practice. SE was also elevated by practice. Consistent with previous findings $[13,14]$, higher court-movement was not associated with a higher net physiological cost. Racket-strategy had no effect on match-play court-movement, physiological cost or SE. Therefore, $\mathrm{R}$ is not a requirement for effective practice with either mode enabling increases in match-play distance and speed.

The ability to push high distances at high speeds is a characteristic associated with high-skill players [14]. Hence, considerable interest in strategies for low-skill playerdevelopment exists in this area. The present study revealed that only a short bout of practice ( 24-min) is required to increase court-movement activity during WT match-play. Novice players pushed further forwards and in overall terms, and attained higher mean peak and average speeds in match-play, post-practice. Such an outcome is positive, with a likely association between greater court-movement and an enhanced response to ball and opponent movement $[13,14]$. Interestingly, increased court-mobility in the present study was associated with unaltered physiological responses, similar to what has been observed in previous LCB strategies [13]. One explanation is that practice-induced increases in chair skills are prompting improvements in mechanical efficiency which offset the likely physiological consequences of increased movement activity. This is plausible as increases in mechanical 
efficiency are caused by changes in propulsion technique [26], and increases in work per cycle, push time, cycle time [25] and efficiency [25,27] are associated with practice. Also, lower EE as a consequence of greater mechanical efficiency is associated with experienced persons who use a wheelchair when compared with novice AB groups [36]. Novices are able to optimise upper body kinematics and dynamics (reduced push frequency and greater work per push) in relatively short periods ( 12-min) [37]. Hence, with greater energetic yield transferred into purposeful work, higher distances and speeds could realistically be achieved with a similar or proportionately lower physiological cost. As previous studies are limited to linear motion on a motorised treadmill, the present study adds considerably to the available literature with consideration of tennis-specific propulsion conditions. WT movement patterns are unpredictable with repeated changes of direction and pace [12]. So while an ability to push further and at greater speeds without increases in physiological markers appears to be desirable for optimal performance, further research is required to confirm this notion.

While novice players have anecdotally stated a preference for the LCB [13], no formal means to capture user experiences has been applied previously. A considerable strength of the present study was inclusion of a tool to measure SE which, coupled with court-movement and physiological data, allowed for data triangulation. In the present study, SE scores were derived from five discrete questions: chair manoeuvrability through ground stroke variants (front- and back-hand swing), ability to return the ball before the second bounce, ability to return the ball to an opponent (within a 2-m radius) and transitioning from pushing to hitting. Increases in the global score can therefore indicate enhanced perceived aptitude for WT-specific propulsion, enhanced ability to assume a strong court position for shot-play, and enhanced ball skills. Given that no drills involved actual ball-to-racket contact, this outcome is noteworthy and suggests that a ball may not be required for effective practice. Thus, practice-induced changes in court-movement are consistent with player perception of increased mastery in WT chair propulsion and shot-play. Given that a lack of perceived skill development has been associated with attrition in individual sports including tennis [38], early mastery of technical aspects is critical in ensuring ongoing participation satisfaction and commitment.

This study revealed lower court-movement for $\mathrm{R}$ practice with lower distance per minute (overall, forwards and reverse), and lower peak and average speeds. This finding is consistent with previous work indicating that power losses [23], and therefore lower peak velocities [15], can be attributed to $\mathrm{R}$ activity. Therefore, $\mathrm{R}$ can be considered a constraint to court-movement during practice. Further, a lower relative mean peak HR for R reveals that lower peak physiological effort is associated with this modality. Completion of WT-specific court-mobility drills without the constraint of a racket may be useful in elevating exercise intensity, and thereby, optimising conditions for health improvement. Racket use should therefore be carefully considered to ensure agreement with training aims and optimisation of health outcomes. While large effect sizes $(d=0.80$ to 1.00$)$ indicated an association between court-movement and increased relative exercise intensity in NR, differences in \%HRavg, $\dot{\mathrm{V}}{ }_{2 \mathrm{P}}$ and $\% \dot{\mathrm{VO}}_{2 \mathrm{P}}$ were not significant. So while greater court-movement may have the potential for elevating exercise intensity, further research involving larger samples is required to support this notion.

Comparatively lower EE is associated with experienced persons who use a wheelchair in comparison to novice and limited skill ( $\sim 3$ week practice) groups [36]. Practice leads to improvements in technique which positively influence efficiency [25]. While this confers advantages for sports performance, with higher proportions of energy transferred into purposeful work, participation for health enhancement is driven by a preference for maximisation of EE. Realistically, the net result of increased proficiency in propulsion skill may be a less physiologically challenging activity environment. Dose-response relationships 
dictate that the magnitude of benefit for any given increase in physical activity is greater for less active persons [39]. Therefore, novices experience greater improvements over shorter time periods than more advanced exercisers. Also, those starting with a less optimal propulsion technique exhibit a faster rate of improvement in gross mechanical efficiency and propulsion technique variables during initial ( 12-min) and cumulative ( $~ 80$-min) bouts of practice [40]. So to maximise EE, strategies for increasing the intensity of the training environment are required to enable positive health outcomes as players develop in their propulsion skill-levels and physical fitness. $\mathrm{R}$ training was associated with a greater proportion of time at low speed (zone 2, 0.50 to $0.99 \mathrm{~m} \cdot \mathrm{s}^{-1}$ ). In contrast, time in high speed zones $\left(\sim 2.00\right.$ to $\left.2.99 \mathrm{~m} \cdot \mathrm{s}^{-1}\right)$ was lower for $\mathrm{R}$ practice. Without a racket, the person using a wheelchair can make more effective contact with the hand rim, with more effective force production, thereby enabling attainment of higher speeds [23]. The present study estimates that $\mathrm{R}$ practice duration would need to be extended to 76-min (minimum) to achieve a target total EE of 300 to $350 \mathrm{kcal}$. In contrast, <60-min of NR practice would achieve a similar energetic effect. This is an important consideration given that recreational court-bookings are normally made in one-hour blocks.

An issue in any research design involving wheelchair sport is the size and constituents of the sample. Populations are typically small and heterogeneous in studies involving persons who use a wheelchair [22]. Also, considerable inter-individual variability exists in motor technique due to bilateral asymmetries [41] and the varying presence of anterior shoulder pain, which develops from repeated pushing [42]. As carefully selected AB individuals have no experience of wheelchair propulsion, prior technique is not a confounding factor. Also, $\mathrm{AB}$ participants can be more easily matched as are not subject to inter-individual variability caused by impairment-specific factors. Hence, sampling this group is particularly suitable for studies such as the present, which are concerned with the rate and / or magnitude of improvement from baseline. In contrast, the requirement for ecological validity should not be overlooked, with research focusing appropriate participants operating in their natural, realworld environment [43]; researchers should be mindful that 'a day in the life' (i.e. simply using a wheelchair for a day) does not equate to a lived experience of someone who uses a wheelchair daily. Due to the inclusive outlook of the ITF, and the lack of a stringent classification system, the range of participants who may choose to play WT is unrestricted and broad. Therefore, wherever possible, studies should seek to recruit persons who use a wheelchair, particularly in cases where attitudes, perceptions or responses of those with a physical impairment are implicated. The present study involved an assessment of SE. whereby a basic psychometric tool was administered [33]. While the tool was appropriate for identification of self-confidence in court-mobility and shot play, questions were limited to five core aspects, with responses given on a seven-point Likert scale, using fixed anchors. Ambiguous terminology (e.g. 'front-hand swing') may need adjustment to enable a more complete understanding and wider revision of the scope, type, range and method of questioning is therefore recommended for future studies to enable a greater understanding of the important area of tennis-specific self-efficacy. The present study involved $A B$ participants, and the merits of this approach have been raised. While this offered novel insight into the role and value of practice in developing confidence in physical skills, considerable work is required to fully understand the perceptions and attitudes of persons who use a wheelchair for sport. Enjoyment motivation is an important yet under-researched consideration currently. Fun and enjoyment have been cited as key drivers for post-SCI sports participation in persons who use a wheelchair [44]. Yet nothing is known about the link between enjoyment and wheelchair tennis compliance and this remains an important area for investigation. A visual analogue scale (VAS) is a popular means to quantify psychophysiological state with precision, with good validity and reliability reported [45]. Inclusion 
of psychometric assessment into future designs using VAS would allow for more precise and accurate data identifying the psychosocial drivers behind different types of tennis participation (practice and match-play conditions).' In summary, research priorities should be carefully considered prior to recruitment, and matched to outcome requirements.

Independent of group, WT court-mobility drills raise SE in chair-mobility and increase overall and forwards distance, and mean peak and average speed during a postpractice bout of match-play. Such characteristics are likely to be desirable and represent enhanced playing ability. Coaches can administer short-term practice sessions for novice players using R or NR drills to equivalent effect, for quick enhancement of WT match-play court-mobility. Even though drills were completed without a ball in the present study, shotplay SE is enhanced by practice, most likely due to an increased perceptual ability for wheelchair manoeuvrability. Therefore, ball-to-racket contact is not necessarily required for effective practice. Indeed, NR practice offers a more stimulating activity environment, with higher relative mean peak exercise intensities prompted by the greater court-movement (distance and speed). These characteristics offer the novice player an ideal opportunity to benefit from an $\mathrm{EE}$ associated with optimal health gains.

Word count 4,147 words

\section{Acknowledgements}

We thank the International Tennis Federation for their support. Appreciation is also extended to all participants who volunteered to participate in this study.

\section{Declaration of Interest Statement}

The authors report no conflicts of interests. 


\section{References}

[1] Richardson EV, Papathomas A, Smith B, et al. The psychosocial impact of wheelchair tennis on participants from developing countries. Disabil \& Rehabil. 2017;39:193-200.

[2] Mat Rosly M, Halaki M, Hasnan N, et al. Leisure time physical activity participation in individuals with spinal cord injury in Malaysia: barriers to exercise. Spinal Cord. 2018;56:806-818.

[3] van den Akker LE, Holla JFM, Dadema T, et al. Determinants of physical activity in wheelchair users with spinal cord injury or lower limb amputation: perspectives of rehabilitation professionals and wheelchair users. Disabil \& Rehabil. 2019;29:1-8.

[4] Kirby RL, Worobey LA, Cowan R, et al. Wheelchair skills capacity and performance of manual wheelchair users with spinal cord injury. Arch Phys Med Rehabil. 2016;97:1761-1769.

[5] Kirby RL, Swuste J, Dupuis DJ, et al. The Wheelchair Skills Test: a pilot study of a new outcome measure. Arch Phys Med Rehabil, 2002;83:10-18.

[6] Kirby RL, Dupuis DJ, Macphee AH, et al. The wheelchair skills test (version 2.4): measurement properties. Arch Phys Med Rehabil, 2004;85:794-804.

[7] Rushton PW, Kirby RL \& Miller WC. Manual wheelchair skills: objective testing versus subjective questionnaire. Arch Phys Med Rehabil, 2012;93:2313-2318.

[8] Newton AM, Kirby RL, Macphee AH, Dupuis DJ \& Macleod DA. (2002). Evaluation of manual wheelchair skills: is objective testing necessary or would subjective estimates suffice? Arch Phys Med Rehabil, 83(9), 1295-1299.

[9] Fliess-Douer O, Vanlandewijck YC, Lubel Manor G et al. A systematic review of wheelchair skills tests for manual wheelchair users with a spinal cord injury: towards a standardized outcome measure. Clin Rehabil, 2010;24:867-886.

[10] Campbell IG, Williams C, \& Lakomy HKA. Physiological responses of wheelchair athletes at percentages of top speed. Br J Sports Med, 1997;31:36-40.

[11] Croft L, Dybrus S, Lenton J, et al. A comparison of the physiological demands of wheelchair basketball and wheelchair tennis. Int J Sports Physiol Perform. 2010;5:301-315.

[12] Roy JLP, Menear KS, Schmid MMA, et al. Physiological responses of skilled players during a competitive wheelchair tennis match. J Strength Cond Res. 2006;20:665-671.

[13] Sindall P, Lenton JP, Malone LA, et al. Effect of low-compression balls on wheelchair tennis match-play. Int J Sports Med. 2014;35: 424-431.

[14] Sindall P, Lenton JP, Tolfrey K, et al. Wheelchair tennis match-play demands: effect of player rank and result. Int J Sports Physiol Perform. 2013;8:28-37.

[15] Goosey-Tolfrey VL, Moss AD. The velocity characteristics of wheelchair tennis players with and without the use of racquets. Adapt Phys Activ Q. 2005;22:291-301.

[16] Goosey-Tolfrey VL, Leicht CA. Field-based physiological testing of wheelchair athletes. Sports Med, 2013;43:77-91.

[17] Rietveld T, Vegter RJK, van der Slikke RMA, et al. Wheelchair mobility performance of elite wheelchair tennis players during four field tests: Inter-trial reliability and construct validity. PLoS One, 2019;6;14(6):e0217514.

[18] Dyrbus S. Tennis goes green: should wheelchair tennis follow? ITF Coaching \& Sport Sci Review. 2012;57:14-15.

[19] Hanton S, Mellalieu SD, Hall R. Self-confidence and anxiety interpretation: a qualitative investigation. Psychol Sport Exerc. 2003;5:477-495. 
[20] Côté-Leclerc F, Boileau Duchesne G, Bolduc P, et al. How does playing adapted sports affect quality of life of people with mobility limitations? Results from a mixed-method sequential explanatory study. Health Qual Life Outcomes. 2017;15:22.

[21] Paulson T, Goosey-Tolfrey V. Current perspectives on profiling and enhancing wheelchair court sport performance. Int J Sports Physiol Perform. 2017;12:275-286.

[22] Valent L, Dallmeijer A, Houdijk H, et al. The effects of upper body exercise on the physical capacity of people with a spinal cord injury: a systematic review. Clin Rehabil. 2007;21:315-330.

[23] de Groot S, Bos F, Koopman J, et al. Effect of holding a racket on propulsion technique of wheelchair tennis players. Scand J Med Sci Sports. 2017;27:918-924.

[24] de Groot S, Bos F, Koopman J, et al. The effect of a novel square-profile hand rim on propulsion technique of wheelchair tennis players. Appl Ergon. 2018;71:38-44.

[25] de Groot S, Veeger DH, Hollander AP, et al. Wheelchair propulsion technique and mechanical efficiency after 3 wk of practice. Med Sci Sports Exerc. 2002;34:756766.

[26] Lenton JP, van der Woude L, Fowler, N, et al. Hand-rim forces and gross mechanical efficiency at various frequencies of wheelchair propulsion. Int $\mathbf{J}$ Sports Med, 2013;34:158-164.

[27] Vegter R, de Groot S, Lamoth CJ, et al. Initial skill acquisition of handrim wheelchair propulsion: a new perspective. Trans Neural Syst Rehabil Eng. 2013;22:104-113.

[28] Sakakibara BM, Miller WC, Souza M, et al. Wheelchair skills training to improve confidence with using a manual wheelchair among older adults: a pilot study. Arch Phys Med Rehabil. 2013;94:1031-1037.

[29] Newbery D, Richards G, Trill S, et al. Wheelchair tennis. In: Goosey-Tolfrey VL, editor. Wheelchair sport: a complete guide for athletes, coaches and teachers. Champaign (IL): Human Kinetics; 2010. p. 167-186.

[30] Sindall P, Lenton JP, Whytock K, et al. Criterion validity and accuracy of global positioning satellite and data logging devices for wheelchair tennis court-movement. J Spinal Cord Med. 2013;36:383-393.

[31] Sindall P, Lenton JP, Cooper RA, et al. Data logger device applicability for wheelchair tennis court-movement. J Sports Sci. 2015;33:327-533.

[32] Mason B, Lenton JP, Rhodes J, et al. Comparing the demands of wheelchair rugby using a miniaturised data logger and radio frequency tracking system. Biomed Res Int. 2014;348048:1-8.

[33] Foulon BL, Martin Ginis KA, Benedict C, et al. The effects of a single wheelchair sports session on physical activity cognitions and behaviour. In: Mohiyeddini C, editor. Advances in the psychology of sports and exercise. Hauppage (NY): Nova Science; 2013. p.181-190.

[34] Grubbs FE. Procedures for detecting outlying observations in samples. Technometrics. 1969;11:1-21.

[35] Cohen J. Statistical power analysis for the behavioural sciences. New Jersey (NJ): Erlbaum Associates; 1988.

[36] Croft L, Lenton J, Tolfrey K, et al. The effects of experience on the energy cost of wheelchair propulsion. Eur J Phys Rehabil Med. 2013;49:865-873.

[37] Vegter RJ, Hartog J, de Groot S, et al. Early motor learning changes in upper-limb dynamics and shoulder complex loading during handrim wheelchair propulsion. $\mathbf{J}$ NeuroEng Rehabil. 2015;12:1-14. 
[38] Molinero O, Salguero A, Tuero C, et al. Dropout reasons in young Spanish athletes: relationship to gender, type of sport and level of competition. J Sport Behav. 2006;29:255-269.

[39] Haskell WL. Health consequences of physical activity: understanding and challenges regarding dose-response. Med Sci Sports Exerc. 1994;26:649-660.

[40] Vegter RJK, Lamoth CJ, de Groot S, et al. Inter-individual differences in the initial 80 minutes of motor learning of handrim wheelchair propulsion. PLoS One. 2014;9:1-10.

[41] Warner MB, Wilson D, Heller MO, et al. Scapular kinematics in professional wheelchair tennis players. Clin Biomech. 2018;53:7-13.

[42] Sosnoff JJ, Rice IM, Hsaio-Wecksler ET, et al. Variability in wheelchair propulsion: a new window into an old problem. Front Bioeng Biotech. 2015;3:1-7.

[43] Churton E, Keogh JWL. Constraints influencing sports wheelchair propulsion performance and injury risk. BMC Sports Sci Med Rehabil. 2013;5:1-10.

[44] Tasiemski T, Kennedy P, Gardner BP, et al. Athletic identity and sports participation in people with spinal cord injury. Adapt Phys Act Q, 2004;21:364-378.

[45] Cella DF, Perry SW. Reliability and concurrent validity of three visual-analogue mood scales. Psychol Reports, 1986;59:827-833. 


\section{table 1. Main effects for match.}

Mean values $( \pm \mathrm{s})$ for match-play completed PRE and POST practice. Values for critical $F_{\text {(df variable, df error), }}$ alpha value $(P)$ and partial Eta squared $\left(\eta_{p}^{2}\right)$ presented. Physiological variables: mean average HR expressed as a percentage of laboratory-measured $\mathrm{HR}$ peak; exercise intensity during tennis match-play $\left(\mathrm{VO}_{2 \mathrm{~T}}\right)$; relative exercise intensity during tennis match-play $\left(\% \mathrm{VO}_{2} \mathrm{~T}\right)$

\begin{tabular}{|c|c|c|c|c|c|c|c|c|c|c|}
\hline & \multicolumn{2}{|c|}{ PRE } & \multicolumn{2}{|c|}{ POST } & \multicolumn{2}{|l|}{$F$} & \multicolumn{2}{|l|}{$P$} & \multicolumn{2}{|c|}{$\eta_{\text {partial }}^{2}$} \\
\hline Overall distance $\left(\mathrm{m} \cdot \mathrm{min}^{-1}\right)$ & 34.5 & (6.9) & 37.5 & (6.9) & 5.008 & (1.14) & 0.042 & * & 0.263 & Large \\
\hline Forwards distance $\left(\mathrm{m} \cdot \mathrm{min}^{-1}\right)$ & 20.5 & (6.9) & 24.2 & (6.9) & 8.220 & (1.14) & 0.012 & * & 0.370 & Large \\
\hline Reverse distance $\left(\mathrm{m} \cdot \mathrm{min}^{-1}\right)$ & 0.7 & $(0.4)$ & 0.7 & $(0.4)$ & 0.725 & $(1,14)$ & 0.409 & & 0.049 & Small \\
\hline Forwards-to-reverse distance $\left(\mathrm{m} \cdot \mathrm{min}^{-1}\right)$ & 13.3 & (1.7) & 12.6 & (1.4) & 4.463 & $(1.14)$ & 0.053 & & 0.242 & Large \\
\hline Peak speed $\left(\mathrm{m} \cdot \mathrm{s}^{-1}\right)$ & 2.22 & $(0.31)$ & 2.51 & $(0.35)$ & 11.667 & (1.14) & 0.004 & * & 0.455 & Large \\
\hline Average speed $\left(\mathrm{m} \cdot \mathrm{s}^{-1}\right)$ & 0.58 & (0.12) & 0.63 & $(0.11)$ & 5.359 & (1.14) & 0.036 & * & 0.277 & Large \\
\hline Mean peak HR $\left(b \cdot \mathrm{min}^{-1}\right)$ & 124 & $(15)$ & 125 & (16) & 0.043 & $(1.14)$ & 0.839 & & 0.003 & \\
\hline Mean minimum HR $\left(b \cdot \min ^{-1}\right)$ & 73 & (15) & 74 & (13) & 2.227 & $(1.14)$ & 0.158 & & 0.137 & Medium \\
\hline Mean average HR $\left(b \cdot \min ^{-1}\right.$ ) & 96 & (17) & 96 & (17) & 0.293 & $(1.14)$ & 0.597 & & 0.021 & Small \\
\hline$\% \mathrm{HR}_{\mathrm{L}}$ & 51.5 & (7.6) & 51.8 & (7.6) & 0.311 & $(1.14)$ & 0.586 & & 0.022 & Small \\
\hline $\mathrm{VO}_{2 \mathrm{~T}}\left(\mathrm{~L} \cdot \mathrm{min}^{-1}\right)$ & 0.75 & $(0.36)$ & 0.76 & $(0.37)$ & 0.257 & (1.14) & 0.620 & & 0.018 & Small \\
\hline$\% \mathrm{VO}_{2 \mathrm{~T}}$ & 28.6 & $(9.1)$ & 29.0 & $(9.5)$ & 0.401 & $(1.14)$ & 0.537 & & 0.028 & Small \\
\hline Self efficacy scale score ${ }^{+}$ & 3.3 & $(0.9)$ & 4.1 & $(0.9)$ & 16.002 & (1.14) & 0.001 & * & 0.533 & Large \\
\hline
\end{tabular}

Self-efficacy scale score accepted as the mean of five responses: 'How confident are you in your ability to: manoeuvre your wheelchair through a front hand swing' (Q1); 'manoeuvre your wheelchair through a back hand swing' (Q2); 'transition the racket hand from pushing to hitting' (Q3) 'hit the ball before two bounces' (Q4); 'return the ball to your opponent within a 2 metre radius' (Q5). *Significant main effect for match denoted in bold type $(P<0.05)$. 


\section{figure 1. Outline of physiological profiling and on-court testing}

Tests sequenced chronologically (left to right). Physiological profiling: initial workload (IW grey dashed line) determined during familiarisation. Workload increased above IW in 15 to $20 \mathrm{~W}$ increments. Minimum four stages, maximum six completed (black and grey blocks respectively). Peak testing commenced at an equivalent workload to final submaximal stage (black dashed line). 15 to $20 \mathrm{~W}$ increments applied at 1-min intervals until volitional exhaustion. †Submaximal and *peak values for $\mathrm{HR}, \dot{\mathrm{VO}}_{2}, \mathrm{BLa}^{-}$and $\mathrm{RPE}$ recorded. Tennis match-play: participant group and number assigned based on physiological profiling and sex. Two 60-min bouts of competitive tennis using an LCB. Organised practice: 8 tennis-specific drills completed with (R) or without (NR) a racket in-hand. Drill order randomised within and between groups (i.e. start at drill 1 progressing in order [1 to 8], or start at drill 8 progressing in a reverse sequence [8 to 1]). Players complete all eight drills once for each condition (with and without racket). One 3-min bout of continuous effort was required for drill completion. A maximum 2-min rest interval was permitted between drills. Drills: $\mathbf{1}=$ down-the-mountain, $\mathbf{2}$ = park-the-car, $\mathbf{3}=$ through-the-gate, $\mathbf{4}=$ sprint-slalom-reverse, $\mathbf{5}=$ two-push-slalom, $\mathbf{6}=$ half-court-map, 7 = agility, $\mathbf{8}=$ box-command [29].

\section{figure 2. Comparison of physiological responses and court-movement variables during organised practice}

Mean values. Error bars denote $\pm \mathrm{s}$. Dashed line (percentage of laboratory-measured peak values): mean peak $\mathrm{HR}$ as a percentage of $\mathrm{HR}_{\mathrm{L}}\left(\% \mathrm{HR}_{\max }\right)$, minimum $\left(\% \mathrm{HR}_{\min }\right)$ and average $\left(\% \mathrm{HR}_{\mathrm{avg}}\right) \mathrm{HR}$; relative exercise intensity during organised practice $\left(\% \dot{\mathrm{VO}}_{2 \mathrm{P}}\right)$. Solid line (physiological variables): mean peak $\left(\mathrm{HR}_{\max }\right)$, minimum $\left(\mathrm{HR}_{\min }\right)$ and average $\left(\mathrm{HR}_{\mathrm{avg}}\right) \mathrm{HR}$; exercise intensity during organised practice $\left(\dot{\mathrm{V}}_{2 \mathrm{P}}\right)$. Stacked data series (distance): forwards (TDf.m), reverse (TDr.m), and forwards-to-reverse counter-movement (TDfr.m) distance. Overall distance (TD.m) for group indicated by sum total of stacked data series. Long dashed line (peak and average speed). *Significant difference between-groups $(P<0.05)$. $T$-test statistic $(t)$, alpha level $(P)$ and ES (Cohen's $d$ ) presented for significant outcomes in descending order of ES.

figure 3. Percentage of time spent in individual speed zones for organised practice with and without a racket

*Denotes significant difference for between-group comparisons at each individual speed zone. 


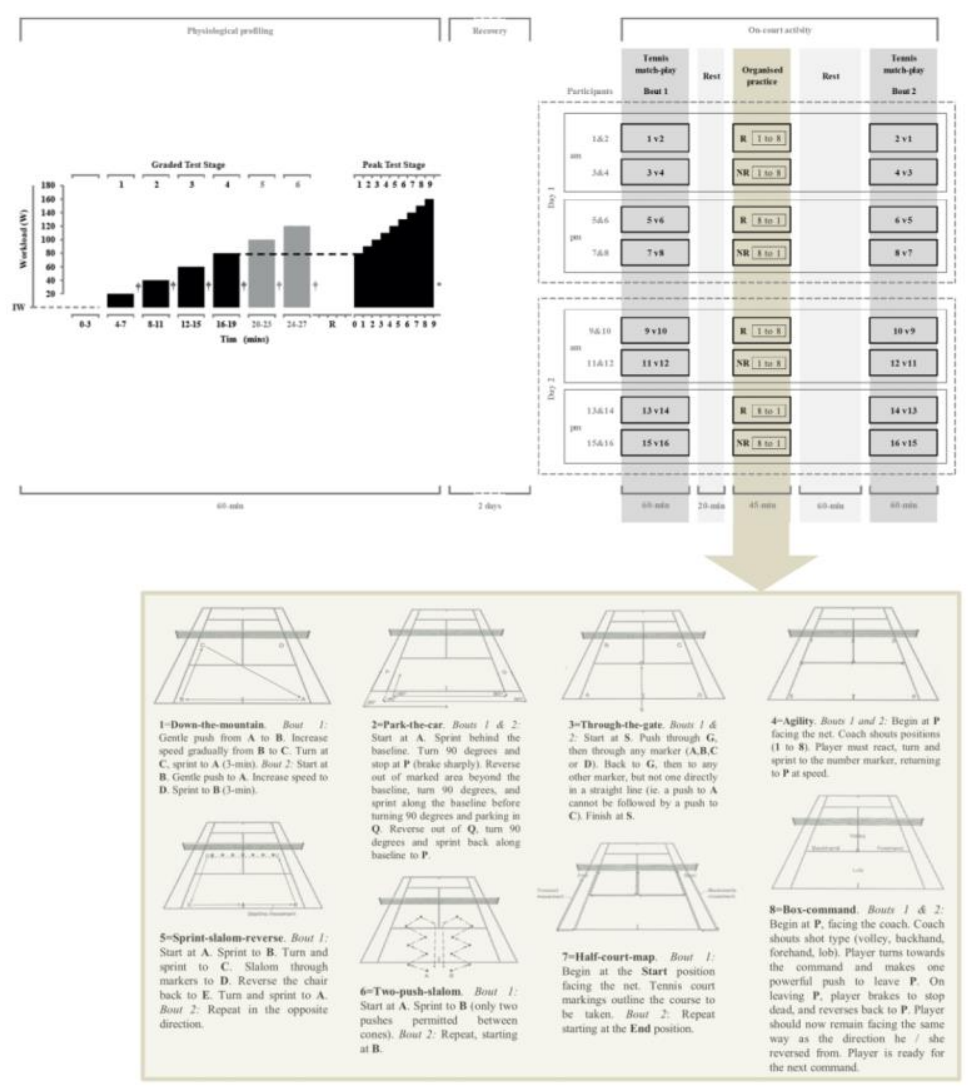

figure 1. Outline of physiological profiling and on-court testing. Tests sequenced chronologically (left to right). Physiological profiling: initial workload (IW - grey dashed line) determined during familiarisation. Workload increased above IW in 15 to $20 \mathrm{~W}$ increments. Minimum four stages, maximum six completed (black and grey blocks respectively). Peak testing commenced at an equivalent workload to final submaximal stage (black dashed line). 15 to $20 \mathrm{~W}$ increments applied at 1-min intervals until volitional exhaustion. +Submaximal and * peak values for $\mathrm{HR}_{1} \mathrm{VO}_{2}, \mathrm{BLa}^{-}$and RPE recorded. Tennis match-play: participant group and number assigned based on physiological profiling and sex. Two 60 -min bouts of competitive tennis using an LCB. Organised practice: 8 tennis-specific drills completed with (R) or without (NR) a racket in-hand. Drill order randomised within and between groups (i.e. start at drill 1 progressing in order [ 1 to 8 ], or start at drill 8 progressing in a reverse sequence [8 to 1$]$ ). Players complete all eight drills once for each condition (with and without racket). One 3-min bout of continuous effort was required for dril completion. A maximum 2-min rest interval was permitted between drills. Drills: 1 = down-the-mountain, $=$ park-the-car, 3 = through-the-gate, $4=$ sprint-slalom-reverse, $5=$ two-push-slalom, $6=$ half-court-map, $7=$ agility, 8 = box-command [22]. 


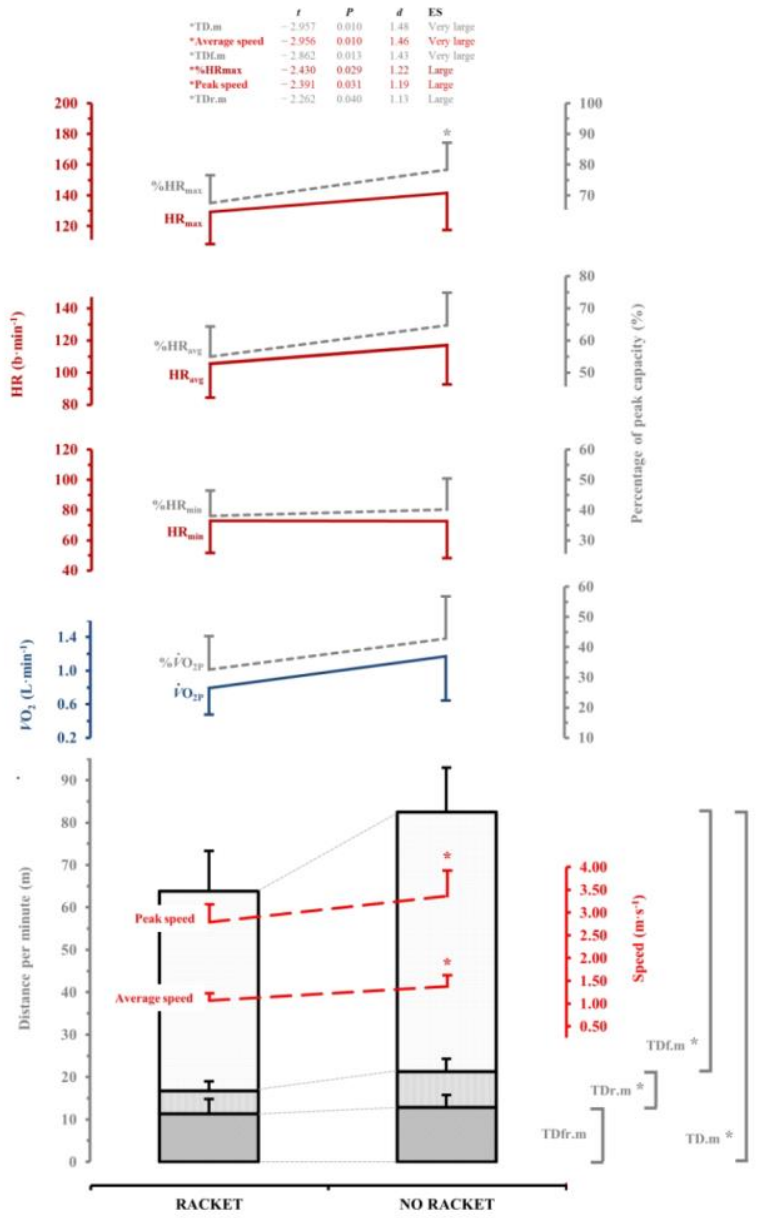

figure 2. Comparison of physiological responses and court-movement variables during organised practice. Mean values. Error bars denote $\pm \mathrm{s}$. Dashed line (percentage of laboratory-measured peak values): mean peak $H R$ as a percentage of $H R L\left(\% H R_{\max }\right)$, minimum $\left(\% H R_{\min }\right)$ and average $\left(\% H R_{a v g}\right) H R$; relative exercise intensity during organised practice $\left(\% \mathrm{VO}_{2} \mathrm{p}\right)$. Solid line (physiological variables): mean peak $\left(H R_{\max }\right)$, minimum $\left(H R_{\min }\right)$ and average $\left(H R_{a v g}\right) H R$; exercise intensity during organised practice $\left(V_{2}\right.$ ). Stacked data series (distance): forwards (TDf.m), reverse (TDr.m), and forwards-to-reverse counter-movement (TDfr.m) distance. Overall distance (TD.m) for group indicated by sum total of stacked data series. Long dashed line (peak and average speed). *Significant difference between-groups $(P<0.05)$. T-test statistic $(t)$, alpha level $(P)$ and ES (Cohen's $d$ ) presented for significant outcomes in descending order of ES. 


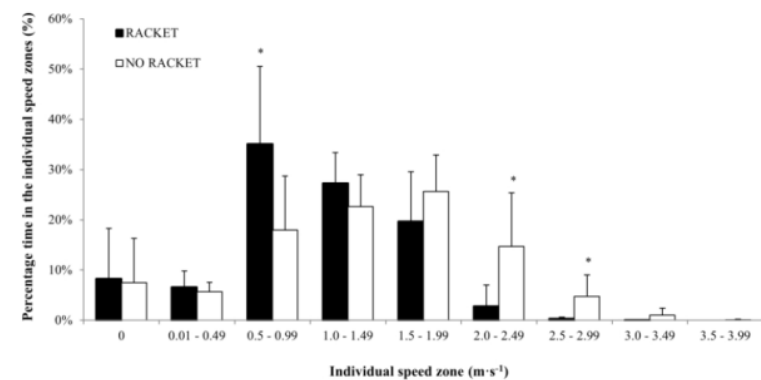

figure 3. Percentage of time spent in individual speed zones for organised practice with and without a racket. *Denotes significant difference for between-group comparisons at each individual speed zone. 